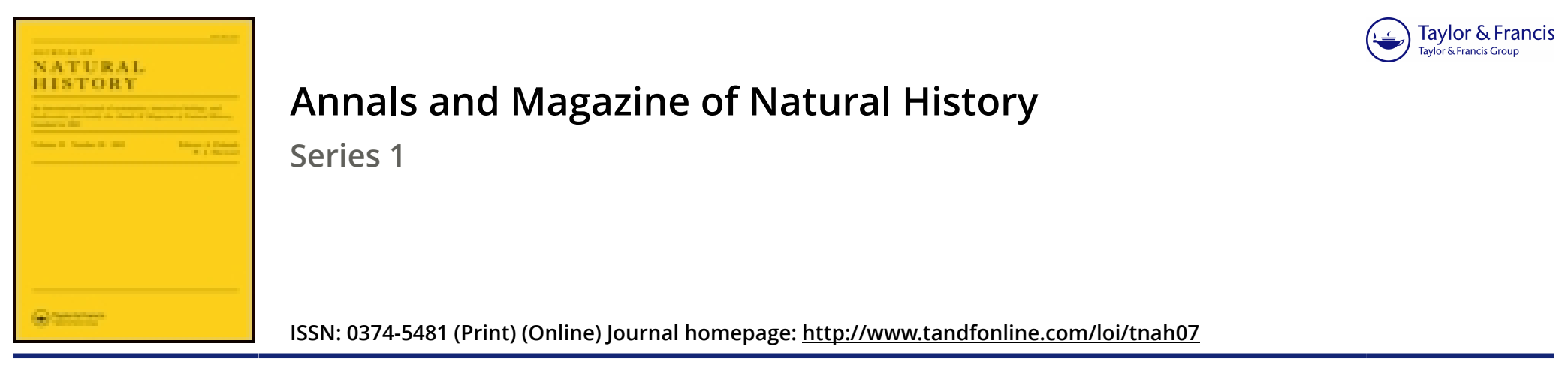

\title{
XXX.-Note on Dr. Meigs's Memoir on the reproduction of the opossum
}

\section{Prof. Richard Owen F.R.S.}

To cite this article: Prof. Richard Owen F.R.S. (1847) XXX.-Note on Dr. Meigs's Memoir on the reproduction of the opossum , Annals and Magazine of Natural History, 20:134, 324-328, DOI: $10.1080 / 037454809496056$

To link to this article: http://dx.doi.org/10.1080/037454809496056

册 Published online: 21 Dec 2009.

Submit your article to this journal $\lceil\pi$

Q View related articles $\sqsubset$ 


\section{XXX.-Note on Dr. Meigs's Memoir on the Reproduction of the Opossum. By Prof. Owen, F.R.S.}

To the Editors of the Annals of Natural History.

\section{Gentlemen,}

I HAVE been favoured by Mr. Everett, the late highly-respected Minister of the United States in this country, with the following extract from the Proceedings of the 'American Philosophical Society' for April 16th, 1847; which, as it contributes to elucidate one of the most singular subjects in the animal œconomy, will no doubt be acceptable to your readers:-

“The Committee (Drs. Hays, Bache and Condie), to whom had been referred the memoir of Dr. Charles D. Meigs, upon the reproduction of Didelphys virginiana, read 19th March 1847, reported, recommending its publication in the Transactions of the Society, which was ordered accordingly.

"Professor Owen's paper on the reproduction of the Kangaroo and the Wombat has left certain points still unsettled as to the reproduction of the marsupials ; and MM. Milne Edwards and Pouchet, in their works, have left uncleared several points, which it is the object of Dr. M.'s paper to explain.

"The terms fatus and embryo cannot properly be applied to the young of the Didelphys while in the pouch; since, when first placed in the marsupium, the young opossum is endowed with all the attributes of a mammiferous quadruped in the full enjoyment of a real warm-blooded respiratory and digestive existence. None of the authors on this subject appear to have investigated the state of the early young; and the most vague and incorrect notions still prevail as to their condition.

"On the 18th of February 1847 , a light snow having fallen, the tracks of two opossums were followed on the 19th over the snow to the trunk of a hollow tree, wherein they had concealed themselves, and from which were taken a full-grown male and female Didelphys. It was supposed, from the appearance of the testes in the male, and the monotrem of the female, that the animals had retired for the rut, is they are rarely found in company at other seasons.

"On the 27th February they were brought to me, and I carefully examined the marsupium, but could discover no trace of any mammary development of the base of the delicate nipples. February 28 th, no change was discovered by inspection or careful palpation of the pouch. On Monday, March Ist, and on Tuesday the 2nd, there was not the least sigu of change in the pouch. On Wednesday the $3 \mathrm{rd}$, the mammary glands were visibly and palpably enlarged. On Thursday, 4th, still larger. On Friday, 5th, hard and swollen. Saturday, 6th, passed without my inspection; but my servant examined the pouch and discovered no young ones at the teats. At 3 P.M. on Sunday, 7th March, I opened the pouch, and discovered the young animals adhering to the nipples.

" Here then was a manifest preparation for the reception of the 
marsupial young, begun on Wednesday the 3rd of March, and completed by Sunday the 7 th, which is four days. Hence it is clear that the notion heretofore entertained, that the embryo makes the teat wherever it happens to take hold, is unfounded, the preparation being as complete as in any other mammal.

"The uterine gestation probably terminated on the night of Saturday March the 6th, or the morning of Sunday the 7th. The rut probably continued as late as the 18 th or 19th February, which is seventeen or eighteen days; possibly the impregnations may have been a few days earlier than the said dates.

"The observation settles at least the question as to one of the reproductive seasons, which in this case was February.

"In Mr. Owen's observation on the kangaroo, the uterine gestation lasted thirty-nine days; but the kangaroo is a large animal in comparison; the opossum rarely being more than fifteen or sixteen pounds in weight.

"Mr. Owen does not mention the preliminary condition of the mammary glands in the kangaroo.

" Thirteen young opossums were attached to as many nipples, all strongly adhering, and busily employed in sucking the milk.

"They moved the fore-arms, and paws, and heads, very freely ; so that to open the sphincter marsupii was to disclose a very lively scene.

"They were of a deep rose tint, and without hair.

"They were of equal size. I pulled one off from the nipple; and the attachment was so strong, that I expected to tear the body in two before I disengaged the mammilla from the stomal pore in which it was engaged. There was no bulb at the end of the nipple after the detachment of the young one.

"No blood about the mouth or on the nipple followed the separation.

"It was removed at 40 minutes past 7 P.M. It weighed exactly three grains and a half.

"From the snout to the end of the tail it was eight-tenths of an inch long.

"Laid in a watch-glass, it moved freely round and round the glass, and turned over on one side and the other.

"Examined by a lens, it respired by two nostrils and by the mouth. It died at ten minutes past nine o'clock, which was one hour and twenty-nine minutes after its separation, though exposed for some time to the cold air of the street.

"The tongue was apparently equal to one-third the magnitude of the head-milk-white, grooved so as to embrace half the cylindrical circumference of the teat, which was pressed, as to its other half, against the vault of the palate. The mouth was a pore, which I could not distinctly discern without a lens; the cavity of the mouth spacious. The diaphragm strong.

" The heart, in its pericardium, large and powerful. 'The liver very large. The stomach filled with milk vesicles, examined under the microscope; the intestinal convolutions distended with milk and chyle, stained yellow with bile; the bladder of urine filled with fluid. 
"Two lungs, each consisting of minute transparent vesicles resembling small soap-bubbles.

"Such is the anatomy of the young opossum of three and a half grains, destined to attain a weight of fifteen or sixteen pounds.

"While lying on the watch-glass, I put the smooth point of a pencil to its stomal pore. The animal sucked at the pencil, and held on so firmly, that I could lift it partly off the glass by it.

" Does this fact show that twenty-four hours earlier it could draw the delicate teat into the orifice?

"The young, having the teat once in the mouth, cannot let it go; nor does it abandon it for many days.

"I could discover no trace of an umbilicus. I sought for it with a good doublet. But it is not to be believed that a breathing, sanguiferous, digesting mammifer can be developed independently of a placenta.

"On Monday March 12th, an animal being removed for dissection weighed twelve grains; it breathed thirty-two times per minute.

"March 18th. A young one weighed eighteen grains. The tail very prehensile.

"I immersed it in a cup of alcohol to kill it for dissection. It did not die in the fluid until it had been immersed in it for sixteen minutes.

" The observations show the marsupial young to have a chylopoietic, warm-blooded, oxidating, innervating, and free-willing life, being as fully endowed with all the means of an independent existence, as the young of the elephant at the teat.

"If this be so, all mystery as to the nature of the life of the marsupial young is at an end."

With regard to the statement, that I omitted to "mention the preliminary condition of the mammary glands in the Kangaroo," I beg to refer to my article Marsupialia, 'Cyclopædia of Anatomy,' t. iii. p. 321 , where, in reference to the female kangaroo experimented on, I state,-“"The right superior nipple was the one in use; it was nearly two inches long and one-third of an inch in diameter; the mammary gland formed a large swelling at its base. The other three nipples were everted and about half an inch in length." - "Sept. 11th, fifteenth day of gestation, nipples in the same condition."_-"Sept. 30th, thirty-fourth day, the nipple in use by the young kangaroo (which has died) is diminished in size." And again : "Oet. 4th, the nipple formerly in use has diminished one-third in size; the other nipples indicate no appearance of approaching parturition." The following day (thirty-ninth of gestation) "the new-born kangaroo was in the pouch and attached to the left superior nipple." Having specified the particular mammary gland which was enlarged, I presumed it would be understood that the others were not enlarged, and formed no swelling at the base of the smaller nipples.

The phrnomena observed and described by Dr. Meigs are 
highly valuable additions to the physiology of the marsupial œconomy, but I must demur to the hypothetical statement, " it is not to be believed that a breathing, sanguiferous, digesting mammifer can be developed independently of a placenta." The young Viper is born alive, breathing, circulating its blood, capable of digestion, and was developed independently of a placenta. Nay, this body is not even essential to the development of an organisin in which respiration and circulation go on so vigorously as to maintain a high degree of temperature, as, for example, in the Bird. The infinite variety, in the works of Creation, of the means by which similar ends are attained, should teach us to subordinate faith in what seems to be a general rule, to observation, wherever observation can be made. One of the most valuable facts in Dr. Meigs' memoir is the determination of the period of gestation in the Didelphys virginiana, viz. from the 18th of February to the 7th of March, with probably a range of a few days more or less.

In order to determine ex visu the nature of the embryonic membranes and appendages, and their degree of correspondence with those of the embryo of the kangaroo, which has no placenta, the female opossums should be sought after in the interval of the dates given by Dr. Meigs, or between the 10th of February and the 10th of March, and the state of the uterus carefully examined. Few series of preparations would be of more importance in elucidating the physiology of marsupial generation than the embryos and membranes of the opossum at different stages of its brief intra-uterine life. Whilst trespassing on your columns, permit me to add the following in reference to a former communication.

My much-esteemed and learned friend Professor Rymer Jones having intimated to me that he had been in the habit of regarding the odontoid process as the body of the atlas ; which, in fact, was the opinion of Cuvier in respect of the odontoid of the Chelys ; I beg, in order to prevent misapprehension, to disclaim any title to originality in the conclusions to which my comparisons of the cervical wedge-bones in recent and extinct Reptilia have led me, beyond the distinction of the body of the atlas into its pcripheral and central parts, and the recognition of the so-called body of the atlas in Man and Mammalia, as still being a part of such element of the atlas, and the odontoid as the complementary (central) part, and not the representative of the entire body of the atlas.

My attention being directed more to the question of the homology of the 'wedge-bones' than of the 'odontoid,' in the paper which I transmitted to you in August last, and which was favoured by a place in the last number of the 'Annals,' I omitted to refer, as $I$ ought to have done, to the passage in the 'Ossemens Fossiles:' 
it is as follows:- "Ce qui prouve que cette pièce, analogue à l'odontoïde, est dans le fait le corps de l'atlas, e'est que dans la Matamata elle se soude aux trois premières, ct prend toute la forme d'une vertèbre, s'articulant avec l'axis, et pourvue, comme lui, en dessous d'une crète longitudinale, et sur les côtés de petites apophyses transverses."-Tome v. part ii. p. 207.

In the Matamata (Chelys fimbriata) I find the piece answering to the first wedge-bone in Enaliosauria, and to that which Cuvier (l. c. p. 96) describes as representing the body of the atlas in the Crocodile, articulating but not confluent with the large odontoid, and articulating also with the fore-part of the base of the neural arch of the atlas. Traces of the suture still exist between the rest of the neural arch of the atlas and the 'odontoid.' The Emys (Cimochelys) longicollis resembles the Chelys in the size and shape of the central part of the body of the atlas. The difference between these and other Chelonia in respect to the odontoid, relates essentially to the greater proportion of the neural arch of the atlas which it supports, concurrently with its larger size.

$I$ have the honour to be, Gentlemen,

Your obedient servant,

London, October 16, 1847.

Richard Owen.

\section{XXXI.-Horce Zoologicce. By Sir William Jardine, Bart., F.R.S.E. \& F.L.S.}

[Continued from vol, xix. p. 83.]

\section{Birds of Tobago.}

VIREO GILVUS, Vieill. N.*

Mr. KInk has appended no note to this species, which from the small number of specimens received does not appear to be very plentiful.

Srurus aquaticus, Swain. Gray-throated Wagtail. N.

"Very little is known of this active and restless little bird; they are in general to be found in the bed or channel of rocky rivers, or by waterfalls, and when surprised will fly to a considerable distance, making a noise similar to that of the European 'Stonechatter.' After alighting they continue to bob up and down the heads, uttering a 'chirk' at every motion, at other times running along the sand nimbly in the manner of the Sandpipers. Feeds on small insects like gnats and ants." We have also received this species from Jamaica.

* Species marked n. are atso found in North America; s. in South America; and N. s. in both. 